OPEN ACCESS

Edited by:

Carlo Sala,

Italian National Research Council, Italy

Reviewed by:

Claudia Lodovichi,

Italian National Research Council, Italy

Eric Hanse

University of Gothenburg, Sweden

*Correspondence:

Veronica Egger

Veronica.Egger@ur.de

${ }^{\dagger}$ These authors share first authorship

Received: 14 April 2020 Accepted: 19 October 2020 Published: 16 November 2020

Citation:

Ona Jodar T, Lage-Rupprecht $V$, Abraham NM, Rose CR and Egger V (2020) Local Postsynaptic Signaling on Slow Time Scales in Reciprocal Olfactory Bulb Granule Cell Spines

Matches Asynchronous Release.

Front. Synaptic Neurosci. 12:551691.

doi: 10.3389/fnsyn.2020.551691

\section{Local Postsynaptic Signaling on Slow Time Scales in Reciprocal Olfactory Bulb Granule Cell Spines Matches Asynchronous Release}

\author{
Tiffany Ona Jodar ${ }^{1,2+}$, Vanessa Lage-Rupprecht ${ }^{1,3+}$, Nixon M. Abraham ${ }^{4}$, \\ Christine R. Rose ${ }^{5}$ and Veronica Egger ${ }^{1 *}$
}

\begin{abstract}
${ }^{1}$ Regensburg University, Regensburg, Germany, ${ }^{2}$ Institut D'Investigacions Biomèdiques, Barcelona, Spain, ${ }^{3}$ Fraunhofer Institute for Algorithms and Scientific Computing, St. Augustin, Germany, ${ }^{4}$ Indian Institute of Science Education and Research, Pune, India, ${ }^{5}$ Heinrich Heine University Duesseldorf, Düsseldorf, Germany
\end{abstract}

In the vertebrate olfactory bulb (OB), axonless granule cells (GC) mediate self- and lateral inhibitory interactions between mitral/tufted cells via reciprocal dendrodendritic synapses. Locally triggered release of GABA from the large reciprocal GC spines occurs on both fast and slow time scales, possibly enabling parallel processing during olfactory perception. Here we investigate local mechanisms for asynchronous spine output. To reveal the temporal and spatial characteristics of postsynaptic ion transients, we imaged spine and adjacent dendrite $\mathrm{Ca}^{2+}$ - and $\mathrm{Na}^{+}$-signals with minimal exogenous buffering by the respective fluorescent indicator dyes upon two-photon uncaging of DNI-glutamate in OB slices from juvenile rats. Both postsynaptic fluorescence signals decayed slowly, with average half durations in the spine head of $\mathrm{t}_{1 / 2} \_\left[\mathrm{Ca}^{2+}\right]_{\mathrm{i}} \sim 500 \mathrm{~ms}$ and $t_{1 / 2} \Delta\left[\mathrm{Na}^{+}\right]_{i} \sim 1,000 \mathrm{~ms}$. We also analyzed the kinetics of already existing data of postsynaptic spine $\mathrm{Ca}^{2+}$-signals in response to glomerular stimulation in $\mathrm{OB}$ slices from adult mice, either WT or animals with partial GC glutamate receptor deletions (NMDAR: GluN1 subunit; AMPAR: GluA2 subunit). In a large subset of spines the fluorescence signal had a protracted rise time (average time to peak $\sim 400 \mathrm{~ms}$, range 20 to $>1,000 \mathrm{~ms})$. This slow rise was independent of $\mathrm{Ca}^{2+}$ entry via NMDARs, since similarly slow signals occurred in $\triangle$ GluN1 GCs. Additional $\mathrm{Ca}^{2+}$ entry in $\triangle$ GluA2 GCs (with AMPARs rendered $\mathrm{Ca}^{2+}$-permeable), however, resulted in larger $\Delta \mathrm{F} / \mathrm{Fs}$ that rose yet more slowly. Thus GC spines appear to dispose of several local mechanisms to promote asynchronous GABA release, which are reflected in the time course of mitral/tufted cell recurrent inhibition.

Keywords: olfactory bulb, granule cell, two-photon (2P) uncaging, two-photon sodium imaging, two-photon calcium imaging, asynchronous release, reciprocal synapse, recurrent inhibition

\section{INTRODUCTION}

In the vertebrate olfactory bulb $(\mathrm{OB})$, the lateral dendrites of the principal mitral and tufted cells are interconnected via local GABAergic interneurons. The most abundant class of these local neurons, the axonless granule cells (GC), mediate self- and lateral inhibitory interactions between $\mathrm{mitral} /$ tufted cells via reciprocal dendrodendritic synapses that on the GC dendrite are housed in large spines (Shepherd, 2004). These reciprocal synapses have been directly demonstrated to play 
a role in odor discrimination and learning (Abraham et al., 2010; Gschwend et al., 2015). Moreover, they are also critically involved in generating bulbar $\gamma$-oscillations (Rall and Shepherd, 1968; Nusser et al., 2001; Lagier et al., 2004), which are thought to contribute to odor coding via synchronization and gating of mitral cell output (e.g., Buonviso et al., 2003; Fukunaga et al., 2014; Osinski and Kay, 2016).

Recordings of dendrodendritic inhibition of mitral cells have revealed that recurrent inhibition happens as a barrage of IPSCs (Isaacson and Strowbridge, 1998; Schoppa et al., 1998). Within this barrage, early IPSCs will occur with a very short latency (below $10 \mathrm{~ms}$ ), but recurrent activity takes several hundreds of milliseconds to subside. While this long tail of recurrent inhibition is unlikely to directly contribute to odor discrimination itself (Uchida and Mainen, 2003; Abraham et al., 2004, 2010), it may well play a role in learning and memory formation (Gschwend et al., 2015; see section "Discussion").

The underlying asynchronous release is at least to a major extent due to processing in GCs, since asynchronous responses were demonstrated following flash photolysis of $\mathrm{Ca}^{2+}$ in mitral cell lateral dendrites (Chen et al., 2000). Moreover, while the massive release of glutamate during the commonly used protocol for mitral cell excitation (20-50 ms depolarization in the voltage-clamp mode) might result in activation of slow release pathways not accessible to unitary transmission, we have shown recently, that local, unitary-like two-photon uncaging of glutamate (TPU) can still cause prolonged release of GABA within a time window of up to $500 \mathrm{~ms}$ post uncaging (Lage-Rupprecht et al., 2020).

As to possible mechanisms for late output, unitary EPSPs evoked by spontaneous mitral/tufted cell input or local TPU are mediated by both AMPA and NMDA receptors, and decaying with a time constant $<50 \mathrm{~ms}$ (as recorded at the GC soma, Bywalez et al., 2015). Thus slower actions downstream of ionotropic receptors would be required to trigger cascades that result in asynchronous release events beyond $100 \mathrm{~ms}$. A number of global mechanisms has been proposed to promote asynchronous release from GC spines. These include a delay of global GC action potentials (AP) due to the prominent $\mathrm{I}_{\mathrm{A}}$ current (Schoppa and Westbrook, 1999; Kapoor and Urban, 2006), and a prolonged $\mathrm{Ca}^{2+}$ entry due to synaptic activation of a non-specific cation current $\mathrm{I}_{\mathrm{CAN}}$, possibly in coincidence with global APs (Hall and Delaney, 2002; Egger, 2008; Stroh et al., 2012).

Since as in other synapses reciprocal release of GABA is $\mathrm{Ca}^{2+}$-dependent (Isaacson and Strowbridge, 1998), how could spine $\mathrm{Ca}^{2+}$ signals mediate asynchronous release? To answer this question, we explored several potential local mechanisms that might be involved in slow spine $\mathrm{Ca}^{2+}$ signaling and thus are directly related to the biophysical properties of individual spines.

While the endogenous $\mathrm{Ca}^{2+}$ buffering capacity $\kappa_{E}$ in GC spines is not unusually high $(\sim 120)$ and thus cannot explain lingering $\mathrm{Ca}^{2+}$, the $\mathrm{Ca}^{2+}$ extrusion from the spine cytosol is sluggish (rate $\gamma \sim 500 \mathrm{~s}^{-1}$ at RT), which might support asynchronous output (Egger and Stroh, 2009).

As to postsynaptic spine $\mathrm{Ca}^{2+}$ signals upon glomerular mitral cell stimulation (100 $\mu$ M OGB-1, Egger et al., 2005), responses in juvenile rat GC spines are robust, with an average amplitude of $\sim 40 \% \Delta \mathrm{F} / \mathrm{F}$, and rise within $\sim 80 \mathrm{~ms}$. Their decay kinetics are slower than those of backpropagating AP-mediated transients, with a clearly bimodal distribution of durations. While $\sim 2 / 3$ of spine signals decayed by half within $\sim 600 \mathrm{~ms}$, the remaining $1 / 3$ decayed very slowly, with half durations beyond $1.5 \mathrm{~s}$. Identical signal properties including the fraction of "slow spines" are observed in response to TPU of glutamate (Bywalez et al., 2015). This unitary postsynaptic $\mathrm{Ca}^{2+}$ entry is mainly mediated by NMDA receptors, with additional contributions by low- and high voltage activated $\mathrm{Ca}^{2+}$ channels and $\mathrm{Ca}^{2+}$-induced $\mathrm{Ca}^{2+}$ release (CICR; Egger et al., 2005). Relief from the $\mathrm{Mg}^{2+}$ block is provided via a local AP (“spine spike," Bywalez et al., 2015), while native GC AMPA receptors are not $\mathrm{Ca}^{2+}$-permeable (Jardemark et al., 1997; Egger et al., 2005).

However, these previous recordings of synaptic fluorescence transients were all performed with the $\mathrm{Ca}^{2+}$ indicator dye OGB$1\left(100 \mu \mathrm{M}, \mathrm{K}_{\mathrm{d}}=200 \mathrm{nM}\right)$. Therefore transients are substantially buffered and do not reflect true kinetics of $\mathrm{Ca}^{2+}$ signals (Egger and Stroh, 2009), even though their observed decay times seem to fit well with the time scale of asynchronous release. Thus here we asked whether synaptic signals are indeed slow, also in comparison to AP-mediated transients, by using a low-affinity $\mathrm{Ca}^{2+}$ dye.

Moreover, we had observed earlier on that the triggering of long-lasting depolarizations in the wake of synaptically evoked GC APs required both NMDA receptor activation and opening of voltage-gated $\mathrm{Na}^{+}$channels $\left(\mathrm{Na}_{\mathrm{v}}\right.$; observed in both juvenile rats and adult mice) and that these long-lasting depolarizations were carried by TRPC1/4 heteromeric channels (Egger, 2008; Stroh et al., 2012). Since we know by now that local postsynaptic inputs can trigger "spine spikes" within the spine head (Bywalez et al., 2015), we hypothesized that already local synaptic signals might involve a long-lasting cationic inward current $\mathrm{I}_{\text {CAN }}$ (via TRPCs or otherwise). To this end, we combined $\mathrm{Na}^{+}$imaging based on the dye SBFI (Rose et al., 1999; Ona-Jodar et al., 2017) with TPU of glutamate.

Finally, we noticed that in spite of similar endogenous $\mathrm{Ca}^{2+}$ dynamics and similar amplitudes of spontaneous and evoked synaptic transients in adult mouse and juvenile rat GCs (Egger et al., 2005; unpublished observations Egger and Stroh, Egger and Stroh, 2009; Abraham et al., 2010), postsynaptic $\mathrm{Ca}^{2+}$ signals in adult mouse GCs were yet slower with regard to their rise time (original data set from Abraham et al., 2010, in which kinetics had not been analyzed quantitatively). This study had revealed a correlation between behavioral performance in a go/no-go odor discrimination task, and modifications of postsynaptic $\Delta \mathrm{Ca}^{2+}$ into the majority of GC spines via viral transfection, across three sample groups: (1) WT mice, (2) mice with a deletion of the GluA2 AMPAR subunit ( $\triangle$ GluA2; increased $\mathrm{Ca}^{2+}$ entry) which resulted in faster discrimination and thus a gain of function, and (3) mice with a deletion of the NR1 NMDAR subunit ( $\Delta$ GluN1, i.e., reduced $\mathrm{Ca}^{2+}$ entry), which resulted in slowed discrimination, i.e., a loss of function. Here we provide a quantitative analysis of the kinetics of the respective $\mathrm{Ca}^{2+}$ signals and the response probability and use the genetic pharmacology provided by the viral knockdown to infer possible mechanisms for the slow rise.

In summary, here we aim to unravel the pyhsiological time courses of postsynaptic $\mathrm{Ca}^{2+}$ and $\mathrm{Na}^{+}$signals in juvenile rat 
GCs in order to investigate their overlap with the previously established time course of asynchronous release. Moreover, we describe an additional potential source of delayed release from adult mouse GC spines.

\section{METHODS}

\section{Juvenile Rat Experiments: Preparation, Electrophysiology}

Sagittal OB brain slices (thickness $300 \mu \mathrm{m}$ ) were prepared in artificial cerebrospinal fluid (ACSF, composition see below) following procedures in accordance with the rules laid down by the EC Council Directive (86/89/ECC) and German animal welfare legislation. Slices were incubated a water bath at $33^{\circ} \mathrm{C}$ for $30 \mathrm{~min}$ and then kept at room temperature $\left(22^{\circ} \mathrm{C}\right)$ until recordings were performed.

The extracellular ACSF was bubbled with carbogen and contained (in mM): $125 \mathrm{NaCl}, 26 \mathrm{NaHCO}_{3}, 1.25 \mathrm{NaH}_{2} \mathrm{PO}_{4}, 20$ glucose, $2.5 \mathrm{KCl}, 1 \mathrm{MgCl}_{2}$, and $2 \mathrm{CaCl}_{2}$. Whole cell current clamp recordings were performed at room temperature $\left(22^{\circ} \mathrm{C}\right)$ and granule cells were held near their resting potential of $-80 \mathrm{mV}$. Granule cells were filled with an internal solution containing the following substances (in $\mathrm{mM}$ ): $130 \mathrm{~K}$-Methylsulfate, 10 HEPES, $4 \mathrm{MgCl}_{2}, 2$ ascorbic acid, 10 phosphocreatine-di-trissalt, $2.5 \mathrm{Na}_{2} \mathrm{ATP}, 0.4 \mathrm{NaGTP}$, and $1 \mathrm{mM}$ SBFI $\left(\mathrm{Na}^{+}\right.$-binding benzofuran isophthalate, Teflabs, Austin, TX, United States and Molecular Probes, Eugene, OR, United States) or 0.1 OGB$6 \mathrm{~F}\left(\mathrm{Ca}^{2+}\right.$ indicator, Thermo Fisher Scientific, Waltham, MA, United States). The patch pipette resistance varied between 6 and $7 \mathrm{M} \Omega$.

\section{Juvenile Rat Experiments: Combined Two-Photon Imaging and Uncaging}

For $\mathrm{Na}^{+}$imaging experiments, electrophysiology and imaging were performed as in Ona-Jodar et al. (2017), and for $\mathrm{Ca}^{2+}$ imaging experiments as in Bywalez et al. (2015). Uncaging is also described in detail in Bywalez et al. (2015). Imaging and uncaging were performed on a Femto-2D-uncage microscope (Femtonics, Budapest, Hungary). Two tunable, Verdi-pumped Ti:Sa lasers (Chameleon Ultra I and II respectively, Coherent, Santa Clara, CA, United States) were used in parallel. The first laser was set either to $840 \mathrm{~nm}$ for excitation of OGB-6F or to $800 \mathrm{~nm}$ for excitation of SBFI in GC spines and dendrites, and the second laser was set to $750 \mathrm{~nm}$ for uncaging of caged glutamate. The two laser lines were directly coupled into the pathway of the microscope with a polarization cube (PBS102, Thorlabs Inc., Newton, NJ, United States) and two motorized mirrors. As caged compound we used DNI-caged glutamate (DNI; Femtonics). DNI was used at $1 \mathrm{mM}$ in a closed perfusion circuit with a total volume of $12 \mathrm{ml}$. Caged compounds were washed in for at least $10 \mathrm{~min}$ before starting measurements. The uncaging laser was switched using an electro-optical modulator (Pockels cell model 350-80, Conoptics, Danbury, CT, United States).

$\mathrm{Na}^{+}$and $\mathrm{Ca}^{2+}$ signals were imaged in line scanning mode with a temporal resolution of $\sim 1 \mathrm{~ms}$. The scan position was checked and readjusted if necessary before each measurement to account for drift.

\section{Adult Mouse GC Ca ${ }^{2+}$ Imaging (Data From Abraham et al., 2010)}

The experiments in adult mice are described in Abraham et al. (2010); the new analyses presented here are based on the very same data set. Briefly (see Abraham et al., 2010, for details), GC-specific deletion of GluA2 AMPAR subunit and GluN1 NMDAR subunit had been achieved by viral expression of Cre recombinase in mice with conditional alleles of GluA2 and GluN1. To restrict the deletion to GCs we had injected rAAV Cre only in the anterior portion with respect to the center of the dorsal OB surface. OB slices had been prepared after an incubation time of at least 2 weeks. GluA2- and GluN1depleted GCs had been identified by somatic fluorescence arising from co-expression of Cre recombinase and Kusabira orange (Tang et al., 2009). Mitral/tufted cells had been activated via glomerular extracellular stimulation, and responding GC spines had been searched for with two-photon $\mathrm{Ca}^{2+}$ imaging in GCs patched below the stimulated glomerulus that had responded to glomerular stimulation with a detectable EPSP (see also Figure 3A).

\section{Data Analysis and Statistics}

Imaging data were analyzed with custom written macros in Igor Pro (Wavemetrics, Lake Oswego, OR, United States), as described previously (Egger et al., 2003, 2005). All imaging signals (OGB-6, OGB-1, SBFI) were analyzed in terms of $\Delta \mathrm{F} / \mathrm{F}=\left(\mathrm{F}(\mathrm{t})-\mathrm{F}_{0}\right) / \mathrm{F}_{0}$. Rise times were measured between 20 and $80 \%$ of the absolute maximal $\Delta \mathrm{F} / \mathrm{F}$ amplitude, and half durations $t_{1 / 2}$ reflect the period from this maximal amplitude to the half-maximal amplitude. SBFI $\Delta \mathrm{F} / \mathrm{F}$ signals were converted into absolute concentration changes $\Delta\left[\mathrm{Na}^{+}\right]_{\mathrm{i}}$ according to the previously established calibration on the same system: for nonsaturating signals a $10 \%$ change in fluorescence emission of SBFI corresponds to a change of $22.3 \mathrm{mM}$ in $\left[\mathrm{Na}^{+}\right]_{\mathrm{i}}$ (Ona-Jodar et al., 2017). The response probability is an estimate of the release probability and was calculated as the ratio of detected responses to the total number $\mathrm{N}$ of stimulations (average $N=14 \pm 5$ in WT).

Statistical comparisons were made with non-parametric tests (Wilcoxon test for paired and Mann-Whitney test for unpaired data sets). Comparisons between WT GC responses and the $\triangle$ GluA2 and $\Delta$ GluN1 GC groups were made via pairwise Mann-Whitney tests with Bonferroni correction. Frequency distributions of parameters were compared with the Kolmogorov-Smirnov test. Mean values are given \pm SD.

\section{RESULTS}

\section{Time Course of Synaptic Spine $\mathrm{Ca}^{2+}$ Signals With Minimal Exogenous Buffering}

To investigate the local mechanisms underlying the asynchronous component of reciprocal GABA release, we 
aimed to detect local postsynaptic $\mathrm{Ca}^{2+}$ signaling in GC spines with as little exogenous buffering as possible, since sluggish extrusion of $\mathrm{Ca}^{2+}$ might also contribute to delayed release (Egger and Stroh, 2009). The low-affinity dye OGB-6F $\left(\mathrm{K}_{\mathrm{d}} \approx 8\right.$ $\mu \mathrm{M}$, Tran et al., 2018) was used at a concentration of $100 \mu \mathrm{M}$, where the kinetics of OGB-6F fluorescence transients in response to single somatic APs $(\Delta \mathrm{F} / \mathrm{F})_{\mathrm{SAP}}$ are identical to the kinetics determined by extrapolation of measurements with varying concentrations of OGB- $1\left(\mathrm{~K}_{\mathrm{d}} \approx 0.2 \mu \mathrm{M}\right)$ to zero added buffer (Egger and Stroh, 2009).

TPU of DNI with similar parameters as in Bywalez et al. (2015; Figure 1A) evoked $\mathrm{Ca}^{2+}$ transients $(\Delta \mathrm{F} / \mathrm{F})_{\mathrm{TPU}}$ in juvenile rat GC spine heads (postnatal days PND11-19), with a mean amplitude of $24 \pm 9 \%$, a mean rise time of $55 \pm 32 \mathrm{~ms}$ and a mean half duration $\mathrm{t}_{1 / 2}$ of $445 \pm 225 \mathrm{~ms}(n=11$ spines, Figures 1B,C). These transients were strictly localized to the spine head (mean $(\Delta \mathrm{F} / \mathrm{F})_{\mathrm{TPU}}$ amplitude in adjacent dendritic shaft $2 \pm 1 \%$, ratio vs. spine head $0.09 \pm 0.03$ ). While $t_{1 / 2}$ was difficult to analyze in some of the individual spine responses because of noise, the averaged transient yielded a $t_{1 / 2}$ of $\sim 550 \mathrm{~ms}$, substantially slower than the half-duration of AP-mediated transients recorded in a subset of these spines $\left(n=8, \mathrm{t}_{1 / 2}\right.$ of averaged $\Delta \mathrm{F} / \mathrm{F} \sim 100 \mathrm{~ms}$, Figure 1B bottom). The influence of buffering on the rise time should be less pronounced since the latter mostly reflects the duration of $\mathrm{Ca}^{2+}$ entry into the cytoplasm. Indeed, the set of rise times is statistically not different from a previous TPU data set using also DNI and OGB-1 (rise time $76 \pm 57 \mathrm{~ms}$, median $60 \mathrm{~ms}, n=42, P=0.19$, Mann-Whitney test; data from Bywalez et al., 2015).

\section{Time Course of Synaptic Spine $\mathrm{Na}^{+}$ Signals With Minimal Added Exogenous Buffering}

Postsynaptic $\mathrm{Na}^{+}$signals could report the activity of the $\mathrm{Ca}^{2+}$ impermeable GC AMPARs and of spine $\mathrm{Na}_{\mathrm{V}} \mathrm{s}$ and TRPC1/4 in a more direct way than $\mathrm{Ca}^{2+}$ signals and thus yield additional information on the state of the locally activated GC spine. We performed two-photon $\mathrm{Na}^{+}$imaging using SBFI at a concentration of $1 \mathrm{mM}$. This is far below both the $\mathrm{Na}^{+}$ concentration of $15 \mathrm{mM}$ in the internal solution and the apparent $\mathrm{K}_{\mathrm{D}}$ of SBFI, so the degree of introduced buffering is negligible (Mondragão et al., 2016; Figure 2).

The ensuing $\mathrm{Na}^{+}$signals following TPU of glutamate at individual spine heads with similar parameters as in the OGB-6F experiments had a mean amplitude of $-(\Delta \mathrm{F} / \mathrm{F})_{\mathrm{TPU}}=4.9 \pm 1.4 \%$ in the spine head of juvenile rat GCs (PND 11-18). They were localized to the spine head to some extent but mostly also detectable in the adjacent dendritic shaft (mean amplitude ratio dendrite/spine $0.56 \pm 0.38$ of spine signal; $P<0.001$ vs. spine signal amplitude; $n=13$ spines in $11 \mathrm{GCs})$. Conversion of the spine signal amplitude to absolute changes in $\left[\mathrm{Na}^{+}\right]_{\mathrm{i}}$ (Rose et al., 1999; Ona-Jodar et al., 2017) yielded a mean increase $\Delta\left[\mathrm{Na}^{+}\right]_{\mathrm{i}}$ by $\sim 10 \mathrm{mM}$. The average rise time was $250 \pm 130 \mathrm{~ms}$ and the half duration $\mathrm{t}_{1 / 2}=890 \pm 770 \mathrm{~ms}$ in the spines, including frequently observed plateau-like phases. Individual $(\Delta \mathrm{F} / \mathrm{F})_{\mathrm{TPU}}$ signals in dendritic shafts were usually too noisy for kinetic analysis.

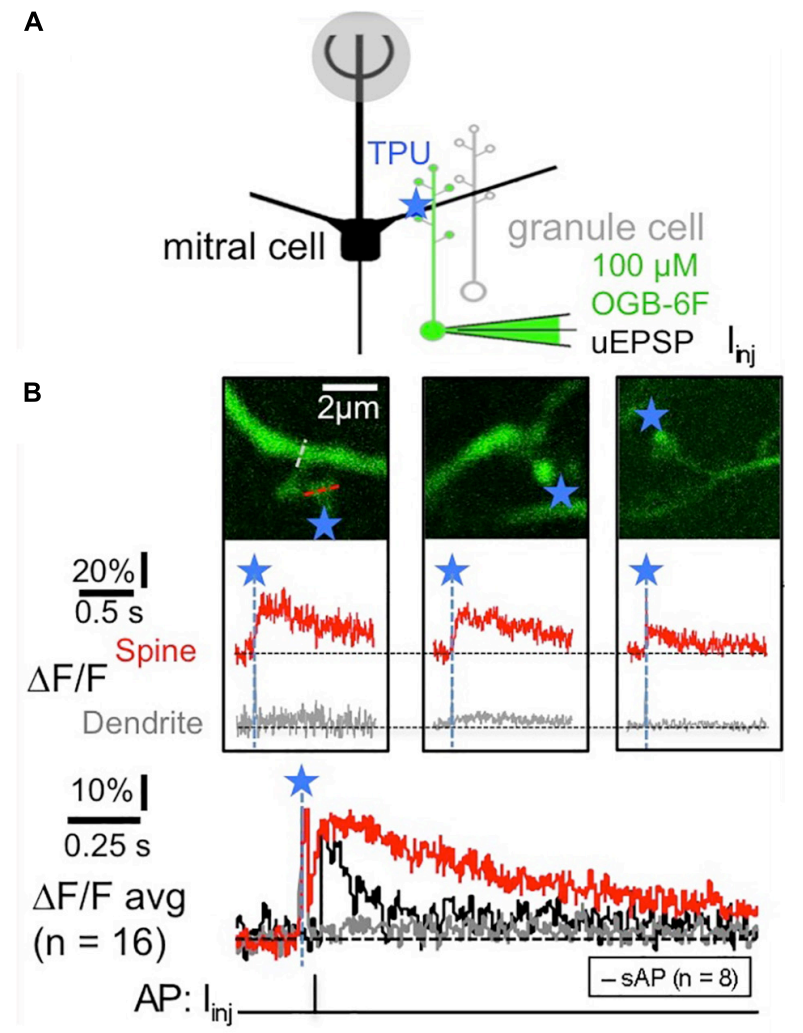

C
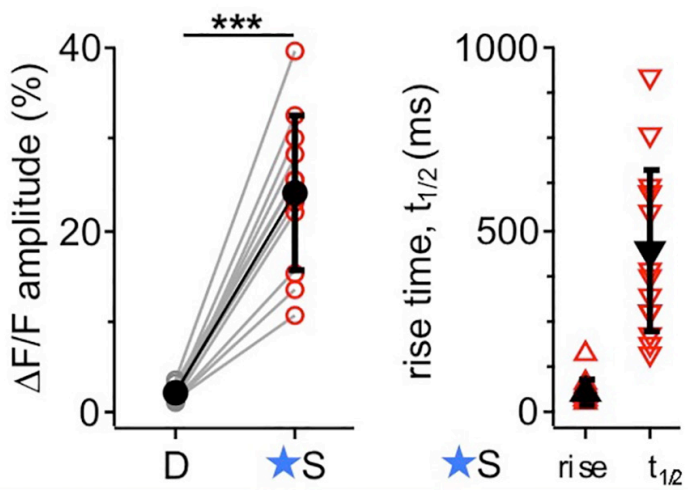

FIGURE 1 | TPU-evoked $\mathrm{Ca}^{2+}$ entry into juvenile rat GC spines with low exogenous buffering. Imaging of TPU-evoked $\mathrm{Ca}^{2+}$ transients within $\mathrm{GC}$ spines with low exogenous buffering (100 $\mu \mathrm{M}$ OGB-6F). (A) Scheme of experiment: whole cell recording from GC (filled with dye via pipette) and TPU at spine head. The pipette was also used for brief current injections to evoke somatic APs (sAP). (B) Top: two-photon scans (z-projections) of three representative examples of individual spines filled with OBG-6F. Blue stars denote uncaging locations. Red and gray dotted line indicate line scan positions. Middle: respective averaged fluorescence transients $(\Delta \mathrm{F} / \mathrm{F})_{\mathrm{TPU}}$ that were collected from line scans across the spine heads above (S, red) and the adjacent dendrite at the base of the spine neck ( $D$, gray). Blue dashed lines and star: time point of uncaging. Bottom: $(\Delta F / F)$ TPU transients averaged across experiments ( $\mathrm{Ca}^{2+}$ imaging: $n=11$ spines) with the same time axis, spine response in red and dendrite response in gray. The black trace in the $\mathrm{Ca}^{2+}$ imaging graph represents the averaged response $(\Delta \mathrm{F} / \mathrm{F})_{\mathrm{AP}}$ to a backpropragating somatically evoked AP (recorded in $n=8$ of the 11 spines). (C) Cumulative plots of $(\Delta F / F)_{T P U}$ amplitudes in dendrite and spine pairs (highly significantly different: $P<0.001$, Wilcoxon test), and of rise times and half durations $t_{1 / 2}$ of $(\Delta F / F)_{T P U}$ within the spine heads (mostly not detectable in the dendrites). 


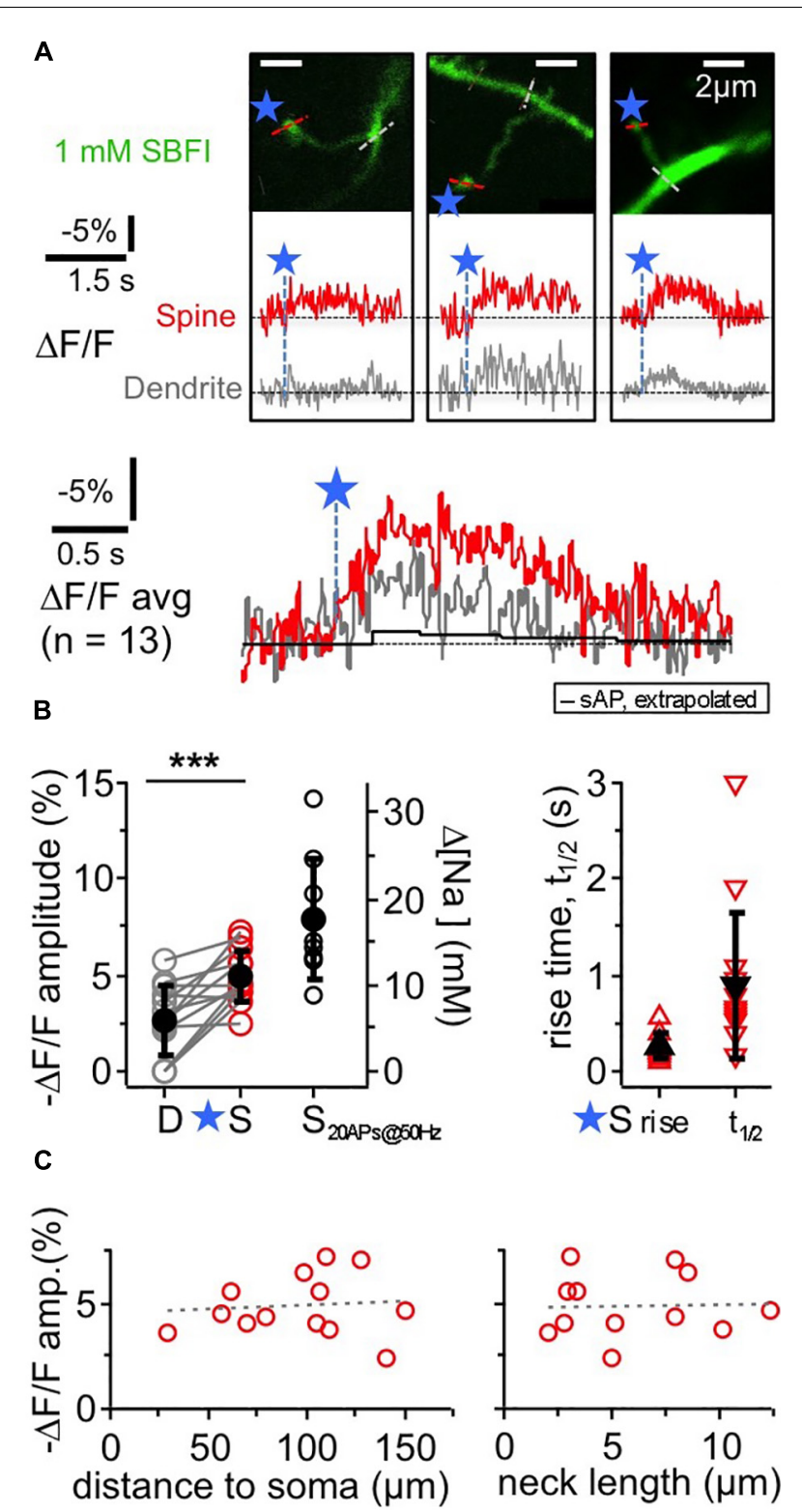

FIGURE 2 | TPU-evoked $\mathrm{Na}^{+}$entry into juvenile rat GC spines. Imaging of TPU-evoked $\mathrm{Na}^{+}$transients within GC spines with low exogenous buffering (1 mM SBFl). Experimental setup as in Figure 1A. (A) See also Figure 1B. Top: two-photon z-stacks of three representative examples of individual spines filled with SBFI. Blue stars denote uncaging locations. Red and gray dotted line indicate line scan positions for the leftmost spine. Middle: respective averaged fluorescence transients $(\Delta F / F)_{T P U}$ within the above spines (S, red) and within the adjacent dendrite (at the base of the spine neck, $\mathrm{D}$, gray). Bottom: $(\Delta \mathrm{F} / \mathrm{F})_{\text {TPU }}$ transients averaged across experiments $(n=13$ spines) with the same time axis, spine response in red and dendrite response in gray. Note the similar time course of the dendritic response. Black trace: extrapolated response $(\Delta \mathrm{F} / \mathrm{F})_{\mathrm{AP}}$ to a single backpropragating somatically evoked AP (from mean response to $20 \mathrm{APs}$ at $50 \mathrm{~Hz}$, see (B) Amplitude $\left.(\Delta \mathrm{F} / \mathrm{F})_{\mathrm{AP}} \approx-0.4 \%, \mathrm{t}_{1 / 2} \approx 1.7 \mathrm{~s}\right)$. (B) Cumulative plots. Left panel: $(\Delta \mathrm{F} / \mathrm{F})_{\mathrm{TPU}}$ amplitudes in dendrite and spine pairs (highly significantly different, $P<0.001$, Wilcoxon test) and $(\Delta \mathrm{F} / \mathrm{F})_{5 \mathrm{OHz}}$ amplitudes in response to a $50 \mathrm{~Hz}$ train of 20 APs in a subset of the same spine heads $(n=9)$. Right axis: changes in $\left[\mathrm{Na}^{+}\right]_{i}$ concentration (calibration from Ona-Jodar et al., 2017). Right panel: half

(Continued)
FIGURE 2 | Continued

durations $t_{1 / 2}$ of $(\Delta F / F)$ TPU within the spine heads ( $t_{1 / 2}$ could not be measured in most dendritic transients because of noise). (C) $(\Delta F / F)$ TPU spine amplitudes vs. distance of the spine to the soma and spine neck length (means $99 \pm 35 \mu \mathrm{m}$ and $5.9 \pm 3.3 \mu \mathrm{m}$ respectively, $n=12$ ). Dashed lines: linear fit. No significant correlations.

As for TPU-evoked $\mathrm{Ca}^{2+}$ transients (Bywalez et al., 2015), there were no significant correlations between spine $(\Delta \mathrm{F} / \mathrm{F})_{\mathrm{TPU}}$ amplitudes and distance to soma or spine neck length (Figure 2C), and also no correlation between the amplitude ratio of spine/dendrite and spine neck length (not shown).

Again, we averaged data across all spine/dendrite pairs (Figure 2A bottom). The averaged spine signal showed an initial plateau-like phase of $\sim 600 \mathrm{~ms}$, and the averaged dendrite signal mirrored the kinetics of the spine signal, which is expected because of the fast diffusion of $\mathrm{Na}^{+}$into the dendrite (Mondragão et al., 2016). Still, these TPU-evoked $\mathrm{Na}^{+}$signals are very slow in view of the overall fast diffusion of $\mathrm{Na}^{+}$and also compared to recent data from synaptic $\mathrm{Na}^{+}$signals in hippocampal pyramidal neuron spines (their $\mathrm{t}_{1 / 2} \sim 20 \mathrm{~ms}$; Miyazaki and Ross, 2017), and therefore are best explained by a persistent influx of $\mathrm{Na}^{+}$(see section "Discussion"). The TPU-evoked spine $\mathrm{Na}^{+}$signals are also very large as compared to the $\mathrm{Na}^{+}$influx induced by single backpropagating APs. The latter was on the order of $0.4 \mathrm{mM}$ (as extrapolated from train stimulation of a subset of the same spines with $20 \mathrm{APs}$ at $50 \mathrm{~Hz}:(\Delta \mathrm{F} / \mathrm{F})_{50 \mathrm{~Hz}}=-7.9 \pm 3.1 \% n=9$, Figure 2B; see Figure 5 in Ona-Jodar et al. (2017) for train responses).

From these experiments we conclude that the time course of asynchronous components of GABA release triggered by unitary activation (Lage-Rupprecht et al., 2020) matches well with substantial and prolonged elevation of postsynaptic $\mathrm{Na}^{+}$ and $\mathrm{Ca}^{2+}$ concentrations in the GC spine. Late release therefore might result from local processing following unitary inputs to the reciprocal spine (see section "Discussion").

\section{Postsynaptic GC Spine $\mathrm{Ca}^{2+}$ Signals in Adult Mice}

As shown above, both postsynaptic $\mathrm{Ca}^{2+}$ and $\mathrm{Na}^{+}$signaling in juvenile rat GC spines is likely to persist for several $100 \mathrm{~ms}$. Moreover, we noticed that in spite of similar endogenous $\mathrm{Ca}^{2+}$ dynamics (with regard to both buffering capacity and extrusion: Egger and Stroh, 2009), postsynaptic spine $\mathrm{Ca}^{2+}$ transients in adult mice evolved yet more sluggishly. Here we analyzed the kinetics and response probability of postsynaptic GC spine $\mathrm{Ca}^{2+}$ signals in response to glomerular stimulation from an earlier data set that was recorded with two-photon fluorescence imaging in acute bulb slices from WT animals or from animals with partial GC GluN1 or GluA2 deletions via viral transfection (PND 36-66; dye 100 MM OGB-1; Abraham et al., 2010).

Postsynaptic $\mathrm{Ca}^{2+}$ transients in WT adult mouse GC spines were also strictly localized to spine heads and occurred with a rather low probability upon glomerular stimulation, even though compound EPSPs were readily recorded at the soma (see Figure 3B), rendering the set of recorded individual responses rather small (estimated response probability $P_{r} 0.10 \pm 0.06$, 
A

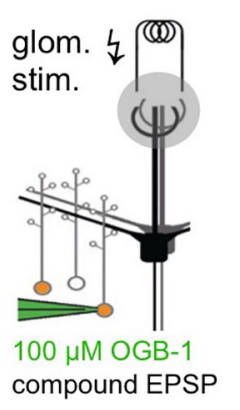

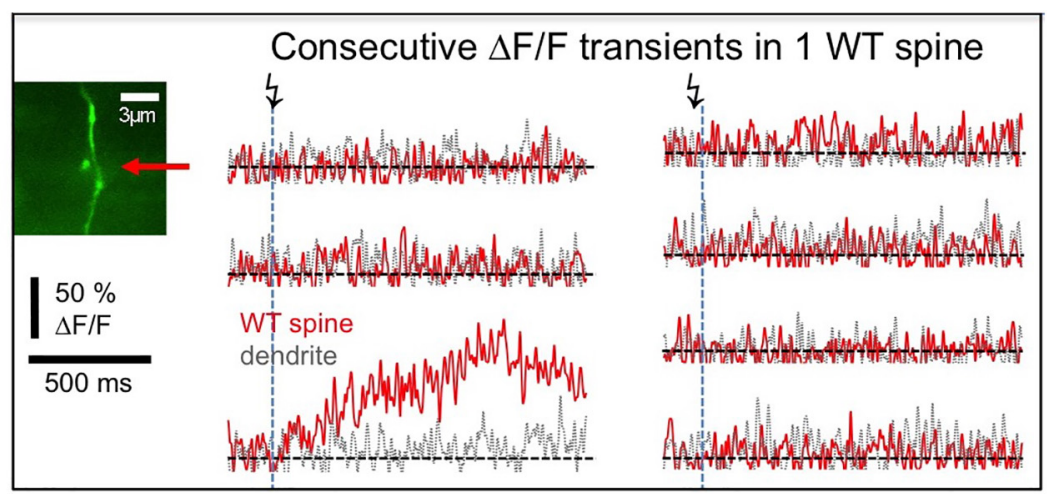

B $\Delta \mathrm{F} / \mathrm{F}$ transients in 5 different spines each, compound EPSP for top transient

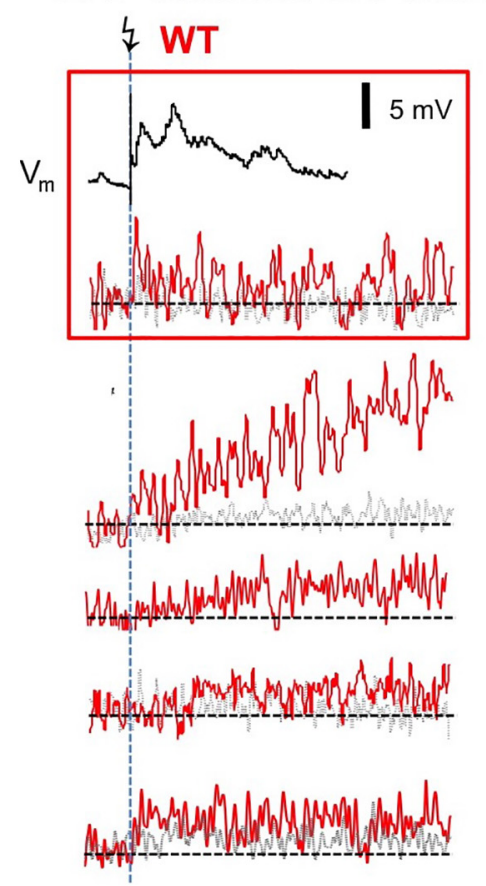

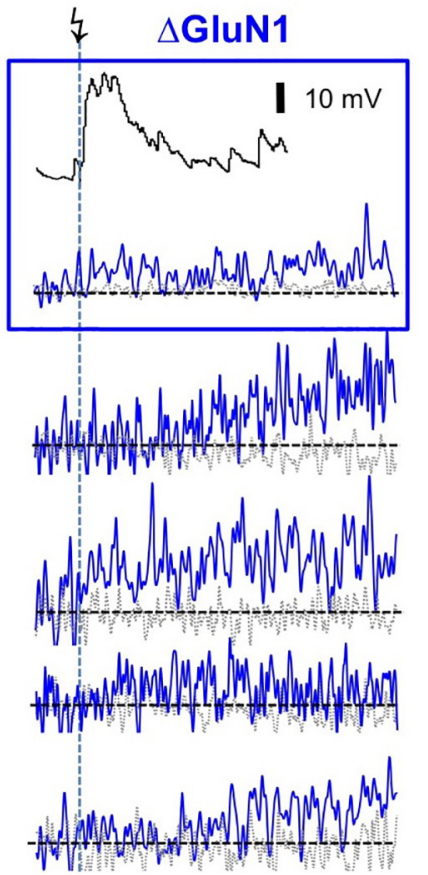

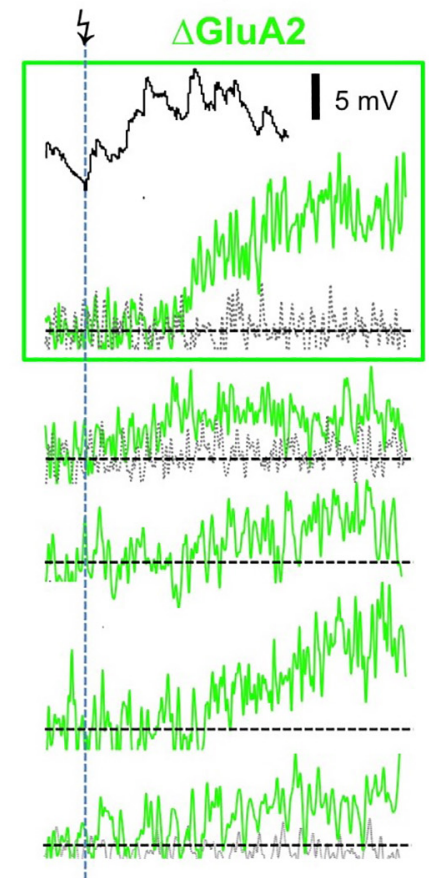

FIGURE 3 | Postsynaptic responses in adult WT, $\Delta$ GluA2 and $\Delta$ GluN1 GC spines. (A) Left: Scheme of experiment (modified from Abraham et al., 2010, their Figure 2). Electrical glomerular stimulation and whole-cell recording of the resulting compound EPSP from a GC, including two-photon imaging of a responding spine and its adjacent dendritic shaft. Genetically modified GCs ( $\Delta$ GluA2 and $\Delta$ GluN1) were identified by the expression of the fluorescent construct Kusabira-Orange. Middle: scan of a WT spine and dendrite. Right: line scans through the spine and dendrite during consecutive glomerular stimulations. Only one response occurred (3rd trace), that shows a slowly evolving $\mathrm{Ca}^{2+}$ transient confined to the spine head. (B) Single responses from other spines, with each trace imaged in a different spine. Same scales for $\triangle F / F$ and time as in (A). Top transients with their associated compound EPSP recordings. Left (red): WT GCs. Middle (blue): $\Delta$ GluN1 GCs. Right (green): $\triangle$ GluA2 GCs. Note the larger size and yet slower evolution compared to WT and $\Delta$ GluN1.

$n=13$ spines; Figures 3A, 4A-C, see section "Methods"). While some responses rose rather quickly (e.g., top left response in Figure 3B, distribution in Figures 4B,C), in most cases the peak amplitude of these $(\Delta \mathrm{F} / \mathrm{F})_{\text {syn }}$ signals occurred several $100 \mathrm{~ms}$ later (average time to peak (TTP) $420 \pm 440 \mathrm{~ms}$, beginning with $20 \mathrm{~ms}, n=14$ events; 2 events with peak beyond scan time of $1,000 \mathrm{~ms}$; if these are included with the end of scan as peak time: $\left.\mathrm{TTP}_{\min }=540 \pm 510 \mathrm{~ms}\right)$. TTP was uncorrelated to peak amplitude $(r=0.32, P=0.11, n=14)$. Such slowly rising signals were never observed in the adjacent dendrite. We also recorded responses to single backpropagating $\mathrm{APs}(\Delta \mathrm{F} / \mathrm{F})_{\mathrm{sAP}}$ in
9 of the 13 spines, with mean rise times of $15 \pm 4$ ms (see also Stroh et al., 2012).

This slow rise was unrelated to $\mathrm{Ca}^{2+}$ entry via NMDARs, since similarly slow signals occurred in $\triangle$ GluN1 GC spines with reduced $\mathrm{Ca}^{2+}$ entry (Figures 3B, 4A-C; $\Delta$ GluN1 TTP $580 \pm 260 \mathrm{~ms}$, beginning with $200 \mathrm{~ms}, n=13$ events; 4 events with peak beyond scan, $\mathrm{TTP}_{\min }=740 \pm 350 \mathrm{~ms}$; no significant difference to WT TTP $\mathrm{Win}_{\text {m }}$ Kolmogorov-Smirnov test $P=0.09)$. The probability to observe such events in $\Delta$ GluN1 GCs $\left(P_{r}=0.18 \pm 0.15, n=7\right.$ spines $)$ was also not significantly different from WT. 
A

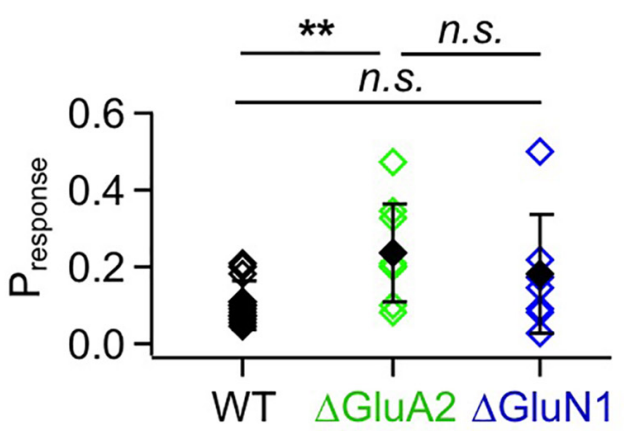

B
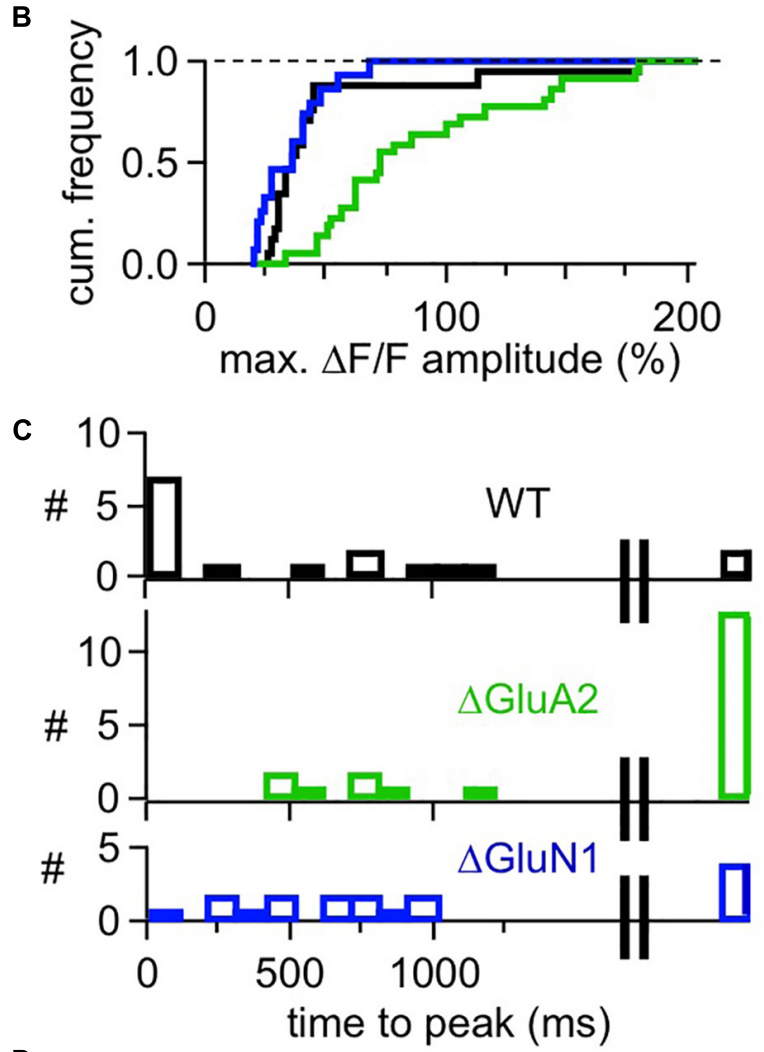

D

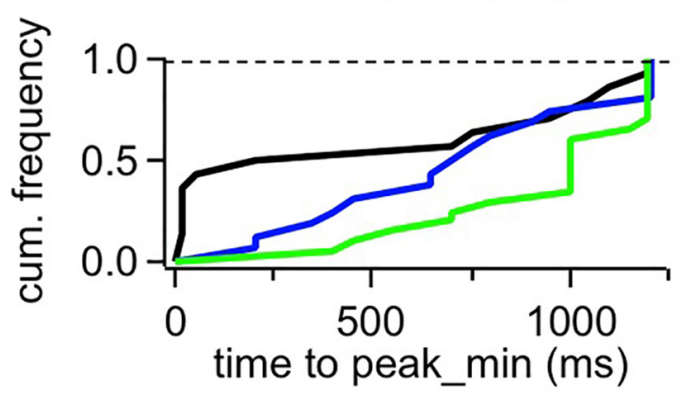

FIGURE 4 | Cumulative analyses of responses in adult mouse WT, $\triangle$ GluA2 and $\Delta$ GluN1 GCs. (A) Estimated likelihood of observing a $(\Delta F / F)_{\text {syn }}$ response upon glomerular stimulation ("response probability," calculated as number of responses divided by number of stimulations). Pairwise comparison (Mann-Whitney test) and Bonferroni: $P_{r}$ WT vs. $\Delta$ GluA2: $P=0.0018, \Delta$ GluA2 vs. $\Delta$ GluN1: $P=0.42$, WT vs. $\Delta$ GluN1: $P=0.51$. (B) Frequency distribution of $(\Delta F / F)_{\text {syn }}$ response amplitudes for the three $G C$ groups. WT is different from

(Continued)
FIGURE 4 | Continued

$\triangle$ GluA2, but not from $\triangle$ GluN1 $(P<0.001$ and $P=0.16$,

Kolmogorov-Smirnov). (C) Distributions of $(\Delta F / F)_{\text {syn }}$ response time to peak for the three GC groups. The rightmost bar shows the responses where the peak might not yet have been reached within the scanning time window (up to $1,200 \mathrm{~ms}$ post stimulation). (D) Frequency distribution of $(\Delta \mathrm{F} / \mathrm{F})_{\text {syn }}$ response time to peak for the three GC groups, with peaks possibly beyond scan window set to $1,200 \mathrm{~ms}$ (minimal time to peak). WT is different from $\triangle \mathrm{GluA2}$, but not from $\Delta$ GluN1 $(P=0.02$ and $P=0.09$, Kolmogorov-Smirnov test).

Additional $\mathrm{Ca}^{2+}$ entry due to GluA2 deletion, however, resulted in larger $\triangle \mathrm{F} / \mathrm{Fs}$ that rose even more slowly than in WT spines (Figures 3B, 4A-C; $\triangle$ GluA2 TTP $680 \pm 250 \mathrm{~ms}$, beginning with $400 \mathrm{~ms}, n=7$ events; 13 events with peak beyond scan; all events: $\mathrm{TTP}_{\min }=960 \pm 270$ ms: KolmogorovSmirnov test $P<0.02$ vs. WT). The probability of such events was significantly higher than in WT $\left(P_{r}=0.24 \pm 0.13, n=8\right.$ spines, $P=0.006$ ), possibly due to their improved detectability because of larger $\Delta F / F$ amplitudes. Such a slow evolution in postsynaptic $\mathrm{Ca}^{2+}$ should also be reflected in the strength and time course of reciprocal GABA release. Indeed, it was shown previously in recordings of mitral cell hyperpolarizing potentials following a train of $20 \mathrm{APs}$ at $50 \mathrm{~Hz}$ (a stimulation that efficiently activates reciprocal release from GCs; Figure 4 in Abraham et al., 2010), that $\Delta$ GluA2 resulted in a significantly stronger and almost two times longer mitral cell recurrent inhibition compared to WT. The relevant time scales match our time to peak data including the late peaks of $(\Delta \mathrm{F} / \mathrm{F})_{\text {syn }}$ reported above ( $\Delta$ GluA2: half duration $\mathrm{t}_{1 / 2} \sim 1,150 \mathrm{~ms}$; WT: $\mathrm{t}_{1 / 2} \sim 600 \mathrm{~ms}$ ). Conversely, $\Delta$ GluN1 did not exert a significant influence on the duration of recurrent inhibition and only a mild reduction on its amplitude, in line with the lack of a significant effect on TTP of $(\Delta \mathrm{F} / \mathrm{F})_{\text {syn }}$ described above (Supplementary Information in Abraham et al., 2010).

\section{DISCUSSION}

\section{Relation Between $\mathrm{Ca}^{2+}$ and $\mathrm{Na}^{+}$ Transients in the GC Spine Head and Asynchronous Release}

Asynchronous release-i.e., release that happens later than the fast coupling of HVA presynaptic $\mathrm{Ca}^{2+}$ currents to the release machinery (e.g., Kaeser and Regehr, 2014)-is a phenomenon known from many central synapses. It is often observed at repetitively stimulated synapses (Wen et al., 2013), which would also hold true for the classical dendrodendritic inhibition protocol, where voltage-clamped mitral cells are being depolarized for 20-50 ms and thus ongoing release of glutamate from mitral cells is likely to happen over dozens of $\mathrm{ms}$ and subsequent asynchronous release of GABA has been documented by many groups (see section "Introduction"). Thus it is at first surprising that local, unitary-like stimulation of GC spines by TPU would suffice to elicit asynchronous release, which we have recently documented (Lage-Rupprecht et al., 2020). However, the temporal extent of this asynchronous release was shorter 
than in the classical dendrodendritic inhibition experiments (maximal extent of $\sim 500 \mathrm{~ms}$ vs. $>1 \mathrm{~s}$ ) and therefore there might be additional mechanisms involved whenever GCs are activated more strongly.

The NMDAR-mediated $\mathrm{Ca}^{2+}$ current into juvenile rat GC spines is expected to recede within less than $200 \mathrm{~ms}$ (e.g., Hestrin et al., 1990; Egger et al., 2005). It is thus on its own unlikely to mediate substantial asynchronous release far beyond the first $100 \mathrm{~ms}$, even though the slow extrusion of $\mathrm{Ca}^{2+}$ from the cytoplasm may contribute to delayed release (Egger and Stroh, 2009). To further unravel signaling downstream of the NMDAR and $\mathrm{Na}_{\mathrm{v}}$ activation during the local spine spike, we investigated the time course of postsynaptic $\mathrm{Na}^{+}$and $\mathrm{Ca}^{2+}$ elevations with minimal exogenous buffering. Both ion species showed prolonged elevations for durations well compatible with asynchronous output.

Previously, somatic AP-mediated and postsynaptic $\mathrm{Ca}^{2+}$ transients recorded with $100 \mu \mathrm{M}$ OGB-1 were observed to decay with roughly equal half durations of $600 \mathrm{~ms}$ (except for the subpopulation of "slow spines" featuring transients with $\mathrm{t}_{1 / 2}>1.5 \mathrm{~s}$, which made up one third; Egger et al., 2005; Bywalez et al., 2015). Whereas here TPU-evoked transients were always substantially longer than AP-evoked transients in the same spine, on the order of 500 vs. $100 \mathrm{~ms}$, dissociating physiological postsynaptic $\mathrm{Ca}^{2+}$ dynamics from exogenous buffer effects. Interestingly, "slow spines" were not observed here, also not in an additional set of $n=12$ spine responses that was excluded from the analysis because of inadvertently longer uncaging intervals. This observation might be explained by the existence of a $\mathrm{Ca}^{2+}$ dependent extrusion mechanism, that is activated only by high levels of $\left[\mathrm{Ca}^{2+}\right]_{\mathrm{i}}$ which are buffered away in the presence of $100 \mu \mathrm{M}$ OGB-1 (such as $\mathrm{Ca}^{2+}$-ATPases, $\mathrm{Na}^{+} / \mathrm{Ca}^{2+}$ exchangers or mitochondrial $\mathrm{Ca}^{2+}$ uniporters, e.g., Sabatini et al., 2002; Chamberland et al., 2019).

In particular, there was a substantial and long-lasting postsynaptic elevation of $\mathrm{Na}^{+}$. This detected $\Delta\left[\mathrm{Na}^{+}\right]_{\mathrm{i}}$ is $\sim 20$ fold higher than what could be extrapolated for a single backpropagating GC AP from responses to train stimulation $(\sim 10$ vs. $\sim 0.4 \mathrm{mM}$, see Figure $2 \mathrm{~A})$. Thus there must be substantial postsynaptic $\mathrm{Na}^{+}$entry on top of local $\mathrm{Na}_{\mathrm{v}}$ activation, in line with earlier reports of $\mathrm{Na}^{+}$signals in response to suprathreshold synaptic stimulation in hippocampal pyramidal neurons (Rose and Konnerth, 2001). In GC spines, the average time course of $\Delta\left[\mathrm{Na}^{+}\right]_{\mathrm{i}}$ showed a plateau-like phase of $>500 \mathrm{~ms}$, very much unlike recent observations of single synaptic $\mathrm{Na}^{+}$ transients in spines of hippocampal pyramidal neurons which decayed within $20 \mathrm{~ms}$ - but were of a similar magnitude ( $\sim 5 \mathrm{mM}$; Miyazaki and Ross, 2017). While the slow decay of the GC spine $\Delta\left[\mathrm{Na}^{+}\right]_{\mathrm{i}}$ might be explained to some extent by the diffusive barrier provided by the high neck resistance (predicted as $\geq 1 \mathrm{G} \Omega$, Bywalez et al., 2015), the origin of the $\left[\mathrm{Na}^{+}\right]_{\mathrm{i}}$ plateau requires a persistent $\mathrm{Na}^{+}$entry that outlasts AMPAR/NMDAR activation. It thus might indeed be related to extended local TRPC1/4 activation downstream of NMDAR activation, since there was no global plateau current in $\triangle$ GluN1 GCs (Stroh et al., 2012).

Alternatively or in addition, the $\left[\mathrm{Na}^{+}\right]_{\mathrm{i}}$ plateau might correspond to a local UP state, i.e., a local plateau potential [which are known to occur in dendrites of e.g., prefrontal pyramidal cells or striatal spiny neurons (Milojkovic et al., 2005; Plotkin et al., 2011)] in the GC spine which could cause TRPC1/4 activation and thus ongoing local influx of $\mathrm{Ca}^{2+}$ sufficient to trigger recurrent release. This influx should also happen close to the release machinery, since buffering of GC $\mathrm{Ca}^{2+}$ by EGTA had no effect on asynchronous release (Isaacson, 2001). Such local UP states or plateau potentials might not be evident in GC somatic membrane potential recordings due to substantial filtering by the large spine neck resistance, even though preliminary simulations of UP states in GC spines show that such plateaus would undergo considerably less filtering that spine spikes because of their slow kinetics (Aghvami and Egger, unpublished observations). So far, evidence for plateau-like states within GC spines could not be gathered from our somatic current clamp recordings; spine recordings with advanced voltage-sensitive dyes would be required to further elucidate this issue. Increased $\left[\mathrm{Na}^{+}\right]_{\mathrm{i}}$ within the observed regime might also provide positive feedback to NMDARs via an upregulation of NMDAR $\mathrm{Ca}^{2+}$ currents by the Src kinase (Yu et al., 1997; Yu and Salter, 1998) and thus cause persistent $\mathrm{Ca}^{2+}$ and $\mathrm{Na}^{+}$entry. Further experiments are required to unravel such interactions.

The large size of $\Delta\left[\mathrm{Na}^{+}\right]_{\mathrm{i}}$ amplitudes in the adjacent dendrite is unexpected, since $\mathrm{Na}^{+}$diffusion from the spine into the dendrite should result in a substantial drop in concentration (e.g., Miyazaki and Ross, 2017) and GC spine necks are particularly long ( $\sim 6 \mu \mathrm{m}$ in our sample, Figure $2 \mathrm{C}$ ). Possible explanations for this observation include the large volume of GC spine heads (similar radius as the dendrite, Egger and Stroh, 2009), weak $\mathrm{Na}^{+}$extrusion from the spine head and neck, or that the source of the synaptically triggered persistent $\mathrm{Na}^{+}$entry mechanism postulated above is present and activated also within the dendritic shaft. In any case, dendritic $\mathrm{Na}_{\mathrm{v}}$ channels (e.g., Egger et al., 2003; Nunes and Kuner, 2018) are unlikely to contribute to this signal since we have shown previously that the postsynaptic spine depolarization undergoes strong attenuation and thus both dendritic $\mathrm{Na}_{\mathrm{v}}$ and $\mathrm{Ca}_{\mathrm{v}}$ channels will not become activated (Bywalez et al., 2015)_unless several spines receive coincident inputs (Müller and Egger, 2020).

\section{Postsynaptic $\mathrm{Ca}^{2+}$ Signals in Adult Mouse vs. Juvenile Rat}

Endogenous $\mathrm{Ca}^{2+}$ buffering and extrusion, postsynaptic $\Delta \mathrm{Ca}^{2+}$ amplitudes and synaptic AP-evoked $\mathrm{Ca}^{2+}$ signals and longlasting depolarizations are similar in adult mouse GCs as in juvenile rat GCs (Egger et al., 2005; Egger, 2008; Egger and Stroh, 2009; Abraham et al., 2010; Stroh et al., 2012). However, a more detailed analysis of the synaptic responses showed also two striking differences. First, we observed a strongly reduced release probability $P_{r}(0.1$ vs. 0.5$)$. This effect might be due to maturation of the bulbar network, since in rats the strength of dendrodendritic inhibition was reported to decline steeply between PND15 and PND20 (Dietz et al., 2011). While this $P_{r}$ value is no more than an estimate due to the small number of recorded responses and substantial noise in some experiments, we observed similar values also for recordings from $\Delta$ GluN1 
and $\Delta$ GluA2 GCs, with the slight increase for $\Delta$ GluA2 possibly explained by the improved detectability of signals in these cells.

Second, yet more strikingly, we observed a broad variability in signal onset and rise. In all three types of GCs, there was a subset of signals with an apparently delayed onset and a very slow evolution within hundreds of milliseconds up to seconds. These features were unchanged between $\mathrm{WT}$ and $\Delta \mathrm{GluN1}$, so NMDARs are not required to generate such responses. Rather, the $\triangle$ GluA2 GCs showed an increased fraction of such slow signals, indicating that $\mathrm{Ca}^{2+}$-permeable AMPARs can also feed into this mechanism. This effect could be mediated perhaps by enhancing postsynaptic $\mathrm{Ca}^{2+}$ induced $\mathrm{Ca}^{2+}$ release (CICR) that we have previously shown to also occur in rat GC spines (Egger et al., 2005). Such a $\mathrm{Ca}^{2+}$-dependent mechanism might also be supported by slow extrusion (Egger and Stroh, 2009). Together with the current observations these data are consistent with voltage-gated $\mathrm{Ca}^{2+}$ channels or $\mathrm{Ca}^{2+}$-permeable AMPARs triggering CICR, rather than NMDARs, as was also observed in other neuron types (e.g., Chávez et al., 2006; Plotkin et al., 2013). In any case, the respective mechanism is also likely to undergo developmental upregulation since a delayed and extended postsynaptic $\mathrm{Ca}^{2+}$ rise was not observed in young rat $\mathrm{GC}$ spines. In adult mice, somatic $\mathrm{GC} \mathrm{Ca}^{2+}$ responses to odorants were also reported to show a high variability with regard to onset and rise (Wienisch and Murthy, 2016).

Intriguingly, apparently slowly rising signals in GC spines may also be of presynaptic origin, e.g., due to late firing of principal neurons in response to glomerular stimulation (Kapoor and Urban, 2006; Gire et al., 2012; Giridhar and Urban, 2012). In our experiments, this source might also contribute in the wake of glomerular stimulation; a correlation with late EPSPs is difficult to test because of the high spontaneous activity and low number of responses in our recordings. However, such delayed presynaptic activity is probably not a main source of slowly rising signals in our data set, since an enhancement of presynaptic signal contributions specifically in $\Delta \mathrm{GluA} 2 \mathrm{GCs}$ appears rather unlikely.

As already implied by this possibility of delayed presynaptic inputs, slow signals in $\mathrm{OB}$ networks are not restricted to GC-mediated recurrent inhibition; representations of olfactory stimuli in general are known to evolve over long time scales of hundreds to thousands of ms (Friedrich and Laurent, 2001; Uchida and Mainen, 2003; Abraham et al., 2004, 2010; Rinberg et al., 2006; Gschwend et al., 2015). Aside from the original notion that these time scales are required for decorrelation of principal neuron activity, persistent representations might also be involved in the formation of odor after-images (Patterson et al., 2013).

With regard to further functions of slow signals, they are at first glance unlikely to play a direct role during odor discrimination or background segregation, since these discriminations usually occur within considerably less than $500 \mathrm{~ms}$, even for difficult mixtures and/or many components (Abraham et al., 2004, 2010; Kepecs et al., 2005; Rokni et al., 2014; Bhattacharjee et al., 2019). Rather, slow signals may be involved in learning and plasticity, also during learning of the mixture discrimination task (Abraham et al., 2004, 2010; Gschwend et al., 2015).
Aberrant slow signals due to pathological changes (extended or reduced asynchronous release) would thus be expected to disrupt plasticity induction. Indeed, several pathologies such as Alzheimer's disease have been associated with enhanced asynchronous release (reviewed in Kaeser and Regehr, 2014), for example at the neuromuscular junction, and interestingly also for fast-spiking interneurons in epileptic foci in both human and rat (Jiang et al., 2012). However, so far no loss of function has been observed for the $\Delta \mathrm{GluA} 2$ modification. Pathological or other modulations of asynchronous release from granule cells might also influence both slow and fast network oscillations, i.e., the respiration coupled $\theta$ and probably more importantly $\gamma$ rhythm that GCs have been associated with (e.g., Fukunaga et al., 2014). Such interactions between asynchronous release and rhythmic activity have been demonstrated in other GABAergic interneurons, including hippocampal cholecystokinin-positive basket interneurons that are crucially involved in generation of the hippocampal theta rhythm (e.g., Hefft and Jonas, 2005), and in cortical parvalbumin-positive GABAergic neurons that power $\gamma$ oscillations (e.g., Traub et al., 1998). Interestingly, increased asynchronous release of GABA might reduce the ability of these PV + neurons to sustain $\gamma$ and has been proposed as one possible mechanism for uncoupling in schizophrenia (Volman et al., 2011).

In conclusion, we find that several mechanisms such as delayed and slowly evolving excitation, slow removal of $\mathrm{Ca}^{2+}$ and perhaps extended local postsynaptic depolarization as indicated by the persistent elevation of $\mathrm{Na}^{+}$may feed into asynchronous GC spine output. Since on the other hand there is also a fast, synchronous component of reciprocal release (Halabisky et al., 2000; Lage-Rupprecht et al., 2020), GC spines are obviously capable of parallel processing on multiple time scales, a property that appears to be further refined with maturation.

\section{DATA AVAILABILITY STATEMENT}

The raw data supporting the conclusions of this article will be made available by the authors, without undue reservation.

\section{ETHICS STATEMENT}

Ethical review and approval was not required for the animal study because according to German animal welfare legislation, our experiments in acute brain slices of rats and mice are classified as in vitro and do not require the approval of an ethics committee. We are, however, monitored and certified by the authorities with regard to animal handling and the preparation process, which involves anesthesia and decapitation.

\section{AUTHOR CONTRIBUTIONS}

Rat granule cell $\mathrm{Ca}^{2+}$ imaging was performed by VL-R, rat granule cell $\mathrm{Na}^{+}$imaging by TOJ, mouse viral injections by NA 
and mouse granule cell $\mathrm{Ca}^{2+}$ imaging by VE. VL-R, TOJ, and VE analyzed the data. VE, NA, and CR designed the research. VE wrote the manuscript. All authors except for TOJ contributed to editing the manuscript.

\section{FUNDING}

This study was funded by the BMBF (German Ministry of Education and Research, FKZ 01GQ1502; VE) with additional equipment funding by DFG-SFB 870 (Deutsche

\section{REFERENCES}

Abraham, N. M., Egger, V., Shimshek, D. R., Renden, R., Fukunaga, I., Sprengel, R., et al. (2010). Synaptic inhibition in the olfactory bulb accelerates odor discrimination in mice. Neuron 65, 399-411. doi: 10.1016/j.neuron.2010.01.009

Abraham, N. M., Spors, H., Carleton, A., Margrie, T. W., Kuner, T., and Schaefer, A. T. (2004). Maintaining accuracy at the expense of speed: stimulus similarity defines odor discrimination time in mice. Neuron 44, 865-876. doi: 10.1016/ s0896-6273(04)00753-6

Bhattacharjee, A. S., Konakamchi, S., Turaev, D., Vincis, R., Nunes, D., Dingankar, A. A., et al. (2019). Similarity and strength of glomerular odor representations define a neural metric of sniff- invariant discrimination time. Cell Rep. 28, 2966-2978.e2965.

Buonviso, N., Amat, C., Litaudon, P., Roux, S., Royet, J.-P., Farget, V., et al. (2003). Rhythm sequence through the olfactory bulb layers during the time window of a respiratory cycle. EJN 17, 1811-1819. doi: 10.1046/j.1460-9568.2003.02619.x

Bywalez, W. G., Patirniche, D., Rupprecht, V., Stemmler, M., Herz, A. V. M., Pálfi, D., et al. (2015). Local postsynaptic voltage-gated sodium channel activation in dendritic spines of olfactory bulb granule cells. Neuron 85, 590-601. doi: 10.1016/j.neuron.2014.12.051

Chamberland, S., Moratalla, A. Z., and Topolnik, L. (2019). Calcium extrusion mechanisms in dendrites of mouse hippocampal CA1 inhibitory interneurons. Cell Calcium 77, 49-57. doi: 10.1016/j.ceca.2018.12.002

Chávez, A. E., Singer, J. H., and Diamond, J. S. (2006). Fast neurotransmitter release triggered by Ca influx through AMPA-type glutamate receptors. Nature 443, 705-708. doi: 10.1038/nature05123

Chen, W. R., Xiong, W., and Shepherd, G. M. (2000). Analysis of relations between NMDA receptors and GABA release at olfactory bulb reciprocal synapses. Neuron 25, 625-633. doi: 10.1016/s0896-6273(00)81065-x

Dietz, S. B., Markopoulos, F., and Murthy, V. N. (2011). Postnatal development of dendrodendritic inhibition in the Mammalian olfactory bulb. Front. Cell Neurosci. 5:10.

Egger, V. (2008). Synaptic sodium spikes trigger long-lasting depolarizations and slow calcium entry in rat olfactory bulb granule cells. EJN 27, 2066-2075. doi: 10.1111/j.1460-9568.2008.06170.x

Egger, V., and Stroh, O. (2009). Calcium buffering in rodent olfactory bulb granule cells and mitral cells. J. Physiol. 587, 4467-4479. doi: 10.1113/jphysiol.2009. 174540

Egger, V., Svoboda, K., and Mainen, Z. F. (2003). Mechanisms of lateral inhibition in the olfactory bulb: efficiency and modulation of spike-evoked calcium influx into granule cells. J. Neurosci. 23, 7551-7558. doi: 10.1523/jneurosci.23-2007551.2003

Egger, V., Svoboda, K., and Mainen, Z. F. (2005). Dendrodendritic synaptic signals in olfactory bulb granule cells: local spine boost and global low-threshold spike. J. Neurosci. 25, 3521-3530. doi: 10.1523/jneurosci.4746-04.2005

Friedrich, R. W., and Laurent, G. (2001). Dynamic optimization of odor representations by slow temporal patterning of mitral cell activity. Science 291, 889-894. doi: 10.1126/science.291.5505.889

Fukunaga, I., Herb, J. T., Kollo, M., Boyden, E. S., and Schaefer, A. T. (2014). Independent control of gamma and theta activity by distinct interneuron networks in the olfactory bulb. Nat. Neurosci. 17, 1208-1216. doi: 10.1038/nn. 3760
Froschungsgemeinsschaft, EG135/5-1) and GSN-LMU. Regensburg University Library provided the open access publication fees.

\section{ACKNOWLEDGMENTS}

We wish to thank A. Pietryga-Krieger for expert technical assistance, Dr. N. Gerkau (Heinrich Heine University Düsseldorf) for initial help with $\mathrm{Na}^{+}$imaging, and $\mathrm{B}$. Rozsa for DNI-glutamate.

Gire, D. H., Franks, K. M., Zak, J. D., Tanaka, K. F., Whitesell, J. D., Mulligan, A. A., et al. (2012). Mitral cells in the olfactory bulb are mainly excited through a multistep signaling path. J. Neurosci. 32, 2964-2975. doi: 10.1523/jneurosci. 5580- 11.2012

Giridhar, S., and Urban, N. N. (2012). Mechanisms and benefits of granule cell latency coding in the mouse olfactory bulb. Front. Neural Circ. 6:40-40.

Gschwend, O., Abraham, N. M., Lagier, S., Begnaud, F., Rodriguez, I., and Carleton, A. (2015). Neuronal pattern separation in the olfactory bulb improves odor discrimination learning. Nat. Neurosc. 18, 1474-1482. doi: 10.1038/nn. 4089

Halabisky, B., Friedman, D., Radojicic, M., and Strowbridge, B. W. (2000). Calcium influx through NMDA receptors directly evokes GABA release in olfactory bulb granule cells. J. Neurosci. 20, 5124-5134. doi: 10.1523/jneurosci.20-13-05124. 2000

Hall, B. J., and Delaney, K. R. (2002). Contribution of a calcium-activated non-specific conductance to NMDA receptor-mediated synaptic potentials in granule cells of the frog olfactory bulb. J. Physiol. 543, 819-834. doi: 10.1113/ jphysiol.2002.024638

Hefft, S., and Jonas, P. (2005). Asynchronous GABA release generates longlasting inhibition at a hippocampal interneuron-principal neuron synapse. Nat. Neurosc. 8, 1319-1328. doi: 10.1038/nn1542

Hestrin, S., Sah, P., and Nicoll, R. A. (1990). Mechanisms generating the time course of dual component excitatory synaptic currents recorded in hippocampal slices. Neuron 5, 247-253. doi: 10.1016/0896-6273(90)90 $162-9$

Isaacson, J. S. (2001). Mechanisms governing dendritic gamma-aminobutyric acid (GABA) release in the rat olfactory bulb. Proc. Natl. Acad. Sci. U.S.A. 98, 337-342. doi: 10.1073/pnas.021445798

Isaacson, J. S., and Strowbridge, B. W. (1998). Olfactory reciprocal synapses: dendritic signaling in the CNS. Neuron 20, 749-761. doi: 10.1016/s08966273(00)81013-2

Jardemark, K., Nilsson, M., Muyderman, H., and Jacobson, I. (1997). Ca2+ ion permeability properties of $(\mathrm{R}, \mathrm{S})$ alpha-amino-3-hydroxy-5-methyl-4isoxazolepropionate (AMPA) receptors in isolated interneurons from the olfactory bulb of the rat. J. Neurophysiol. 77, 702-708. doi: 10.1152/jn.1997. 77.2.702

Jiang, M., Zhu, J., Liu, Y., Yang, M., Tian, C., Jiang, S., et al. (2012). Enhancement of asynchronous release from fast-spiking interneuron in human and rat epileptic neocortex. PLoS Biol. 10:e1001324. doi: 10.1371/journal.pbio. 1001324

Kaeser, P. S., and Regehr, W. G. (2014). Molecular mechanisms for synchronous, asynchronous, and spontaneous neurotransmitter release. Ann. Rev. Physiol. 76, 333-363. doi: 10.1146/annurev-physiol-021113-170338

Kapoor, V., and Urban, N. N. (2006). Glomerulus-specific, long-latency activity in the olfactory bulb granule cell network. J. Neurosci. 26, 11709-11719. doi: 10.1523/jneurosci.3371-06.2006

Kepecs, A., Uchida, N., and Mainen, Z. F. (2005). The sniff as a unit of olfactory processing. Chem. Sens. 31, 167-179. doi: 10.1093/chemse/bjj016

Lage-Rupprecht, V., Zhou, L., Bianchini, G., Aghvami, S. S., Rózsa, B., SassoéPognetto, M., et al. (2020). Presynaptic NMDA receptors cooperate with local action potentials to implement activity-dependent GABA release from the reciprocal olfactory bulb granule cell spine. bioRxiv [Preprint]. 440198. 
Lagier, S., Carleton, A., and Lledo, P.-M. (2004). Interplay between local GABAergic interneurons and relay neurons generates gamma oscillations in the rat olfactory bulb. J. Neurosci. 24, 4382-4392. doi: 10.1523/jneurosci.5570-03. 2004

Milojkovic, B. A., Radojicic, M. S., and Antic, S. D. (2005). A strict correlation between dendritic and somatic plateau depolarization in the rat prefrontal cortex pyramidal neurons. J. Neurosci. 25, 3940-3951. doi: 10.1523/jneurosci. 5314-04.2005

Miyazaki, K., and Ross, W. N. (2017). Sodium dynamics in pyramidal neuron dendritic spines: synaptically evoked entry predominantly through AMPA Receptors and removal by diffusion. J. Neurosc. 37, 9964-9976. doi: 10.1523/ jneurosci.1758-17.2017

Mondragão, M. A., Schmidt, H., Kleinhans, C., Langer, J., Kafitz, K. W., and Rose, C. R. (2016). Extrusion versus diffusion: mechanisms for recovery from sodium loads in mouse CA1 pyramidal neurons. J. Physiol. 594, 5507-5527. doi: $10.1113 /$ jp272431

Müller, M., and Egger, V. (2020). Dendritic integration in olfactory bulb granule cells: threshold for lateral inhibition and role of active conductances upon simultaneous activation. PLoS Biol. doi: 10.1371/journal.pbio. 3000873

Nunes, D., and Kuner, T. (2018). Axonal sodium channel NaV1.2 drives granule cell dendritic GABA release and rapid odor discrimination. PLoS Biol. 16:e2003816. doi: 10.1371/journal.pbio.2003816

Nusser, Z., Kay, L. M., Laurent, G., Homanics, G. E., and Mody, I. (2001). Disruption of GABAA receptors on GABAergic interneurons leads to increased oscillatory power in the olfactory bulb network. J. Neurophysiol. 86, 2823-2833. doi: $10.1152 /$ jn.2001.86.6.2823

Ona-Jodar, T., Gerkau, N. J., Sara Aghvami, S., Rose, C. R., and Egger, V. (2017). Two-photon $\mathrm{Na}(+)$ imaging reports somatically evoked action potentials in rat olfactory bulb mitral and granule cell neurites. Front. Cell Neurosci. 11:50.

Osinski, B. L., and Kay, L. M. (2016). Granule cell excitability regulates gamma and beta oscillations in a model of the olfactory bulb dendrodendritic microcircuit. J. Neurophysiol. 116, 522-539. doi: 10.1152/jn.00988.2015

Patterson, M. A., Lagier, S., and Carleton, A. (2013). Odor representations in the olfactory bulb evolve after the first breath and persist as an odor afterimage. Proc. Natl. Acad. Sci. U.S.A. 110, E3340-E3349.

Plotkin, J. L., Day, M., and Surmeier, D. J. (2011). Synaptically driven state transitions in distal dendrites of striatal spiny neurons. Nat. Neurosci. 14, 881-888. doi: 10.1038/nn.2848

Plotkin, J. L., Shen, W., Rafalovich, I., Sebel, L. E., Day, M., Chan, C. S., et al. (2013). Regulation of dendritic calcium release in striatal spiny projection neurons. J. Neurophysiol. 110, 2325-2336. doi: 10.1152/jn.00422.2013

Rall, W., and Shepherd, G. M. (1968). Theoretical reconstruction of field potentials and dendrodendritic synaptic interactions in olfactory bulb. J. Neurophysiol. 31, 884-915. doi: 10.1152/jn.1968.31.6.884

Rinberg, D., Koulakov, A., and Gelperin, A. (2006). Sparse odor coding in awake behaving mice. J. Neurosci. 26, 8857-8865. doi: 10.1523/jneurosci.0884-06.2006

Rokni, D., Hemmelder, V., Kapoor, V., and Murthy, V. N. (2014). An olfactory cocktail party: figure-ground segregation of odorants in rodents. Nat. Neurosc. 17, 1225-1232. doi: 10.1038/nn.3775

Rose, C. R., and Konnerth, A. (2001). NMDA receptor-mediated Na+ signals in spines and dendrites. J. Neurosci. 21, 4207-4214. doi: 10.1523/jneurosci.21-1204207.2001

Rose, C. R., Kovalchuk, Y., Eilers, J., and Konnerth, A. (1999). Two-photon Na+ imaging in spines and fine dendrites of central neurons. Pflügers Archiv. 439, 201-207. doi: 10.1007/s004249900123
Sabatini, B., Oertner, T. G., and Svoboda, K. (2002). The life cycle of Ca2+ ions in dendritic spines. Neuron 33, 439-452. doi: 10.1016/s0896-6273(02)00573-1

Schoppa, N. E., Kinzie, J. M., Sahara, Y., Segerson, T. P., and Westbrook, G. L. (1998). Dendrodendritic inhibition in the olfactory bulb is driven by NMDA receptors. J. Neurosci. 18, 6790-6802. doi: 10.1523/jneurosci.18-17-06790.1998

Schoppa, N. E., and Westbrook, G. L. (1999). Regulation of synaptic timing in the olfactory bulb by an A-type potassium current. Nat. Neurosci. 2, 1106-1113. doi: $10.1038 / 16033$

Shepherd, G. M. (2004). Olfactory Bulb. The Synaptic Organization of the Brain. Oxford: Oxford University Press.

Stroh, O., Freichel, M., Kretz, O., Birnbaumer, L., Hartmann, J., and Egger, V. (2012). NMDA receptor-dependent synaptic activation of TRPC channels in olfactory bulb granule cells. J. Neurosci. 32, 5737-5746. doi: 10.1523/jneurosci. 3753-11.2012

Tang, W., Ehrlich, I., Wolff, S. B., Michalski, A. M., Wolfl, S., Hasan, M. T., et al. (2009). Faithful expression of multiple proteins via 2A-peptide self- processing: a versatile and reliable method for manipulating brain circuits. J. Neurosci. 29, 8621-8629. doi: 10.1523/jneurosci.0359-09.2009

Tran, V., Park, M. C. H., and Stricker, C. (2018). An improved measurement of the $\mathrm{Ca}(2+)$ - binding affinity of fluorescent $\mathrm{Ca}(2+)$ indicators. Cell Calcium 71 , 86-94. doi: 10.1016/j.ceca.2018.01.001

Traub, R. D., Spruston, N., Soltesz, I., Konnerth, A., Whittington, M. A., and Jefferys, G. R. (1998). Gamma-frequency oscillations: a neuronal population phenomenon, regulated by synaptic and intrinsic cellular processes, and inducing synaptic plasticity. Prog. Neurobiol. 55, 563-575. doi: 10.1016/s03010082(98)00020-3

Uchida, N., and Mainen, Z. F. (2003). Speed and accuracy of olfactory discrimination in the rat. Nat. Neurosci. 6, 1224-1229. doi: 10.1038/ nn 1142

Volman, V., Behrens, M. M., and Sejnowski, T. J. (2011). Downregulation of parvalbumin at cortical GABA synapses reduces network gamma oscillatory activity. J. Neurosci. 31, 18137-18148. doi: 10.1523/jneurosci.3041-11.2011

Wen, H., Hubbard, J. M., Rakela, B., Linhoff, M. W., Mandel, G., and Brehm, P. (2013). Synchronous and asynchronous modes of synaptic transmission utilize different calcium sources. eLife 2:e01206.

Wienisch, M., and Murthy, V. N. (2016). Population imaging at subcellular resolution supports specific and local inhibition by granule cells in the olfactory bulb. Sci. Rep. 6:29308. doi: 10.1038/srep29308

Yu, X.-M., Askalan, R., Keil, G. J., and Salter, M. W. (1997). NMDA channel regulation by channel-associated protein tyrosine kinase src. Science 275:674. doi: 10.1126/science.275.5300.674

Yu, X.-M., and Salter, M. W. (1998). Gain control of NMDA-receptor currents by intracellular sodium. Nature 396, 469-474. doi: 10.1038/24877

Conflict of Interest: The authors declare that the research was conducted in the absence of any commercial or financial relationships that could be construed as a potential conflict of interest.

Copyright (c) 2020 Ona Jodar, Lage-Rupprecht, Abraham, Rose and Egger. This is an open-access article distributed under the terms of the Creative Commons Attribution License (CC BY). The use, distribution or reproduction in other forums is permitted, provided the original author(s) and the copyright owner(s) are credited and that the original publication in this journal is cited, in accordance with accepted academic practice. No use, distribution or reproduction is permitted which does not comply with these terms. 